\title{
Anadolu Mandası Dışkılarından Enterekok Türlerinin İzolasyonu ve Antibiyotik Dirençliliklerinin Tespiti*
}

\author{
Sezen Ak ${ }^{1}$, Timur Gülhan² \\ ${ }^{\text {I} B a f r a ~ I ̇ l c ̧ e ~ G ı d a ~ T a r ı m ~ v e ~ H a y v a n c ı l l k ~ M u ̈ d u ̈ r l u ̈ g ̆ ̈ ̈, ~ B a f r a, ~ S a m s u n ~}$ \\ ${ }^{2}$ Ondokuz Mayls Üniversitesi, Veteriner Fakültesi, Mikrobiyoloji AD, Samsun
}

Geliş Tarihi / Received: 13.02.2018, Kabul Tarihi / Accepted: 13.04.2018

\begin{abstract}
Özet: Enterokoklar normal sindirim sistemi florasında bulunmakla birlikte, özellikle Enterococcus faecalis ve E. faecium gibi türler, insan ve çok sayıda hayvan türünde önemli hastalıklar oluşturmaktadır. Mandaların diğer hayvanlarda olduğu gibi bazı hastalıkların duyarlı hayvan popülasyonlarına ve insanlara bulaştırılmasında rol oynadıkları bilinmektedir. Bu çalışmada Samsun ili ve ilçelerinde yetiştiriciliği yapılan Anadolu mandalarına ait 1000 dışkı örneği enterokok türleri yönünden selektif zenginleştirme standart kültürel metodu ile incelendi. Örneklerin 100'ünden (\%10) E. faecalis, 92'sinden (\%9.2) E. faecium, 48'inden (\%4.8) E. hirae ve 32'sinden (\%3.2) de E. durans olmak üzere, toplam 272 $(\% 27.2)$ enterokok izole ve identifiye edildi. İzolatlar vankomisin ve teikoplanine $\% 2.9$, trimetofrin-sülfamethaksole $\% 3.7$, ampisiline $\% 5.1$, penisiline $\% 7.4$, sefoperazone $\% 8.8$, basitrasine $\% 15.4$, streptomisine $\% 19.9$, amikasin ve gentamisine $\% 20.6$, tetrasikline $\% 26.5$ ve eritromisine $\% 33.8$ oranında dirençli bulundu. İzolatların 126 'sında (\%46.3) iki ve daha fazla antibiyotiğe direnç tespit edilmesi, çoğul antibiyotik dirençliliği açısından önemli olarak değerlendirildi. $\mathrm{Bu}$ araştırma ile bölgemizde ilk kez Anadolu mandalarına ait dışkı örnekleri enterokok türleri açısından incelendi. Araştırmadan elde edilen verilerin, yöremizde yapılacak benzer çalışmalara kaynak teşkil edebileceği kanısına varıldı.
\end{abstract}

Anahtar kelimeler: Anadolu mandası, Antibiyotik direnci, Dışk1, Enterokok

\section{Isolation of Enterococci Species From Anatolian Buffaloes and Determination of Antibiotic Resistances}

\begin{abstract}
Although enterococci found in the normal gastrointestinal flora, especially species such as Enterococcus faecalis and E. faecium, cause important infections in people and a large number of animals. Buffaloes as in other animals known to play a role in certain diseases transmitted to susceptible animals and human populations. In this study, 1000 fecal samples collected from Anatolian buffaloes in breeding Samsun and around were examined for Enterococcus species using selective enrichment standard cultural methods. In total 272 (27.2\%) Enterococcus including 100 (10\%) E. faecalis, $92(9.2 \%)$ E. faecium, 48 (4.8\%) E. hirae and 32 (3.2\%) E. durans were isolated and identified from samples. The isolated strains were found to be resistance to vancomycin and teicoplanin $2.9 \%$, trimethoprim+sulfamethoxazole $3.7 \%$, ampicillin $5.1 \%$, penicillin $7.4 \%$, cefoperazone $8.8 \%$, bacitracin $15.4 \%$, streptomycin $19.9 \%$, amicasin and gentamicin $20.6 \%$, tetracycline $26.5 \%$ and erythromycin $33.8 \%$. Of 272 isolates in $126(46.3 \%)$ detecting resistance to two or more antibiotics was considered significant in terms of multiple antibiotic resistance. Fecal samples obtained from Anatolian buffaloes were examined first time in our region respect to Enterococcus species. We concluded that the data obtained this research can constitute a resource to similar studies in our region.
\end{abstract}

Key words: Anatolian Buffaloes, Antibiotic resistance, Feces, Enterococci

\section{Giriş}

Enterokoklar g1da endüstrisinde starter kültür olarak da kullanılan önemli bir bakteri grubunu oluşturmaktadır [13]. Enterokok cinsi içerisinde 20'den fazla tür bulunmaktadır. Pek çoğu probiyotik olarak kullanılabilecek kadar zararsız bakteriler olmakla birlikte bazıları ciddi hastalıklara neden olabilmektedir [7]. Enterokok türleri çevresel şartlara dayanıklılığ 1 ile çevresel kontaminant bakterilerin başın- da gelmektedir. Dışk1 ile kontamine çiğ veya az 1S1sal işlem görmüş gidaların tüketilmesi sonucu sindirim sistemi enfeksiyonları görülmektedir [8]. Ayrıca pek çok enterokok türü sahip olduğu çeşitli virülens faktörleri ve antibiyotiklere dirençlilik karakterleri açısından insanlardaki hastane enfeksiyonlarının başlıca etkeni olarak karşımıza çıkmaktadır [21]. Enterokoklar normal sindirim sistemi florasinda bulunmakla birlikte, özellikle Enterococcus faecalis ve E. faecium gibi türlerin, insan ve çok sayıda hay-

*Aynı isimli yüksek lisans tezinden özetlenmiştir.

Yazışma adresi / Correspondence: Timur Gülhan, Ondokuz Mayıs Üniversitesi, Veteriner Fakültesi, Mikrobiyoloji AD, Samsun E-posta: timur.gulhan@omu.edu.tr 
van türünde bazı önemli enfeksiyonlara yol açtıkları ortaya konulmuştur. Bazı enterokok türlerinin zoonotik öneme sahip olduğu belirlenmiştir [18].

Manda (Bubalus bubalis), et, süt ve çeki hayvanı olarak dünya çapında, özellikle belirli ülkelerde yaygın olarak, yetiştirilen bir hayvandır. Evcil ve yabani formlardan köken alan mandaların yaklaş1k 74 ırkı bulunmaktadır. Bu 1rklar kabaca, bataklık ve ırmak mandaları olarak ikiye ayrılmaktadır. Bataklık mandaları yük hayvanı olarak kullanılırken, ırmak mandaları et ve süt yönlü yetiştirilmektedir. Türkiye'deki mandalar, ırmak mandalarının bir alt grubu olan Akdeniz mandalarından köken almakta ve Anadolu mandası olarak tanımlanmaktadır. Dünya çapında yaklaşık olarak 177 milyon manda bulunmaktadır. Ülkemizde 158.000 civarında manda yetiştirildiği, Samsun ilinde ise yaklaşık 20. 000 manda bulunduğu bildirilmektedir [2].

$\mathrm{Bu}$ çalışma, Samsun ili ve ilçelerinde halk elinde yoğun olarak yetiştiriciliği yapılmakta olan Anadolu mandalarına ait dışkı örneklerinde enterokok türlerinin belirlenmesi amaciyla gerçekleştirildi. Enterokok türlerinin manda popülasyonlarında sıklığı, yaygınlığı ve dağılımı araştırıldı. İzolatların farklı türden antibiyotik gruplarına olan dirençlilik/ duyarlılık özellikleri ortaya konuldu.

\section{Materyal ve Metot}

Dışkı Örnekleri: Çalışmanın materyalini Samsun ilçelerindeki Anadolu mandalarına ait 1000 adet dışk1 örneği oluşturdu. Bu amaçla alınan dışkı say1ları ve merkezler Şekil 1 ve Tablo 1'de sunuldu.

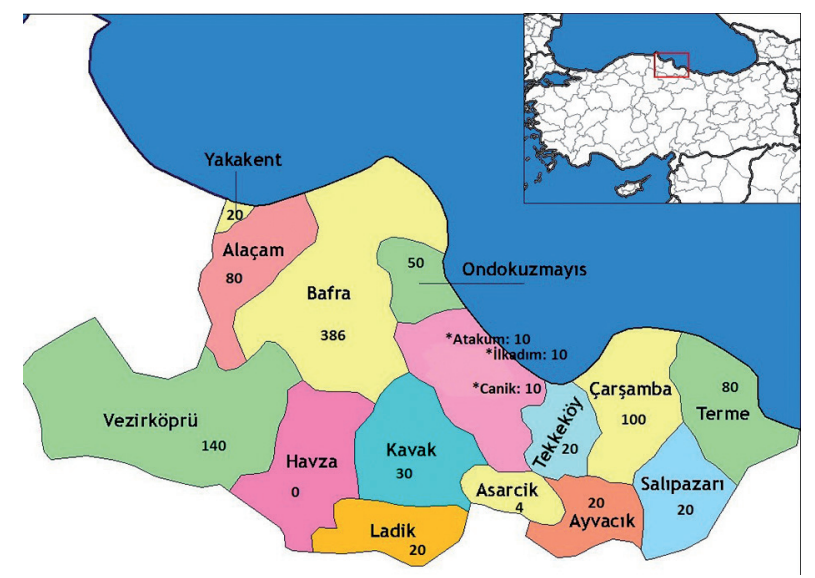

Şekil 1. Anadolu mandası dışkı örneklerinin toplandığı merkezler
Tablo 1. Anadolu mandası dışkı örneklerinin toplandığ 1 merkezler ve dışkı sayıları

\begin{tabular}{lcc}
\hline Merkez & Manda sayısı & Alınan dışkı sayısı \\
\hline Bafra & 8765 & 386 \\
Vezirköprü & 2869 & 140 \\
Alaçam & 1936 & 100 \\
Çarşamba & 1857 & 80 \\
Terme & 1496 & 80 \\
Ondokuz Mayıs & 1116 & 50 \\
Kavak & 428 & 30 \\
Ladik & 408 & 20 \\
Asarcık & 335 & 20 \\
Salıpazarı & 206 & 20 \\
Tekkeköy & 148 & 20 \\
Yakakent & 79 & 20 \\
Atakum & 62 & 10 \\
Canik & 42 & 10 \\
İlkadım & 20 & 10 \\
Ayvacık & 6 & 4 \\
Toplam & $\mathbf{1 9 . 7 7 3}$ & $\mathbf{1 0 0 0}$ \\
\hline
\end{tabular}

Besiyerleri ve Test Kiti: Dışk1 örneklerinde enterokok izolasyonu ve identifikasyonu amaciyla azide dextrose broth (ADB, Difco), bile esculine agar (BEA, Difco), blood agar base (Oxoid), brain heart infusion broth (BHIB, Oxoid), triptic soy agar (TSA, Oxoid) ve mueller-hinton agar (MHA, Oxoid) besiyerleri kullanıld1. Besi yerleri prospektüslerine uygun olarak hazırlandı. Ayrıca şüpheli kolonilerin L-Pyrrolidonyl- $\beta$-Naphthylamide (PYR) aktivitelerinin belirlenmesinde PYR strip test kiti (Bioanalyse, Türkiye) kullanıldı.

İzolasyon ve İdentifikasyon: D1şkı örneklerinden enterokok türlerinin selektif izolasyonu amacıyla dışkı örnekleri transport ve ön zenginleştirme ADB içerisinde $37^{\circ} \mathrm{C}$ ' de 24-48 saat inkübasyondan sonra, bu besiyerinden bile esculin agar (BEA)'a ekimler yapılarak aynı şartlarda inkübasyona bırakıld1. Eskulin pozitif (siyah renkli) kolonilerden, Gram pozitif, PYR pozitif, katalaz negatif, kok morfolojisinde olanlar \% 7 koyun kanlı agara ekilerek saflaştırıldı. İzolatlar, tür tayini ve sonrasında antibiyotik duyarlılıklarının belirlenmesi için \% 10'luk BHI'de $-20{ }^{\circ} \mathrm{C}$ 'de saklandı. İzolatların tür düzeyinde identifikasyonu amaciyla \%6.5'luk NaCl'de üreme, $\% 0.1$ tetrazoliumda üreme, hareket, potasyum tellürit (\%0.04) redüksiyonu ve arjinin hidrolizi ile 
arabinoz, arbutin, sorbitol, sorboz, sukroz, laktoz, mannitol, inulin, raffinoz fermantasyon testleri konvansiyonel yöntemlere göre yapıldı [26].

Antibiyotik Duyarlılık Testi: İzolatların vankomisin $(30 \mu \mathrm{g})$, teikoplanin $(30 \mu \mathrm{g})$, ampisilin (10 $\mu \mathrm{g})$, amikasin $(30 \mu \mathrm{g})$, basitrasin $(10 \mu \mathrm{g})$, eritromi$\sin (15 \mu \mathrm{g})$, gentamisin $(10 \mu \mathrm{g})$, kanamisin $(30 \mu \mathrm{g})$, penisillin $(10 \mu \mathrm{g})$, sefaperazon $(75 \mu \mathrm{g})$, streptomisin $(10 \mu \mathrm{g})$, tetrasiklin $(30 \mu \mathrm{g})$, ve trimetofrin-sülfamethaksol $(1.25$ ve $23.75 \mu \mathrm{g})$ antibiyotiklerine dirençlilik/duyarlılık durumlarının belirlenmesinde standart disk difüzyon tekniği kullanıldı [4].

\section{Bulgular}

İzolasyon ve İdentifikasyon Sonuçları: İzole edilen enterokok türlerinin dışkı örneklerinin sağland1ğ1 merkezlere göre dağılımı ve dışk1 sayıları Tablo 2'de sunuldu.

Antibiyogram Testi Sonuçları: İzole edilen enterokok türlerinin 12 farklı antibiyotiğe duyarlıl1k/dirençlilik sonuçları Tablo 3'de gösterildi. İzole edilen enterokok türlerinde çoğul antibiyotik dirençliliği değerlendirildiğinde; 272 suştan 126'sında (\%46.3) iki ve daha fazla antibiyotiğe direnç tespit edildi. Test edilen 12 antibiyotikten 9'una 2, 8'ine 2, 7'sine 2, 5'ine 4, 4'üne 10, 3 'üne 30 ve 2 'sine de 76 izolatın birlikte dirençli olduğu görül- dü. İzolatların çoklu antibiyotik direnç patternleri Tablo 4'de sunuldu.

Tablo 2. Enterokok türlerinin izole edildiği merkezlere göre dağılımı

\begin{tabular}{|c|c|c|c|c|c|c|}
\hline Merkez & 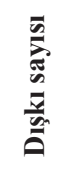 & 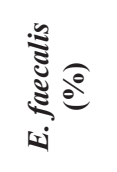 & 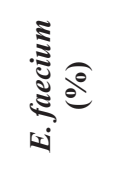 & 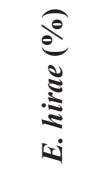 & 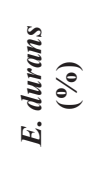 & 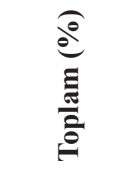 \\
\hline Bafra & 386 & $20(5.2)$ & 14(3.6) & $12(3.1)$ & $10(2.6)$ & $56(14.5)$ \\
\hline Vezirköprü & 140 & $10(7.1)$ & $8(5.7)$ & $6(4.3)$ & $4(2.9)$ & $28(20)$ \\
\hline Alaçam & 100 & $8(8)$ & $10(10)$ & $4(4)$ & $4(4)$ & $26(26)$ \\
\hline Çarşamba & 80 & $10(12.5)$ & $8(10)$ & $4(5)$ & $4(5)$ & $26(26)$ \\
\hline Terme & 80 & $8(10)$ & $10(12.5)$ & $4(5)$ & $2(2.5)$ & $24(30)$ \\
\hline $\begin{array}{l}\text { Ondokuz } \\
\text { Mayis }\end{array}$ & 50 & $10(20)$ & $8(16)$ & $2(4)$ & $4(8)$ & $24(48)$ \\
\hline Kavak & 30 & $6(20)$ & $8(26.7)$ & $4(13.3)$ & $2(6.7)$ & $20(66.7)$ \\
\hline Ladik & 20 & $4(20)$ & $4(20)$ & $2(10)$ & $2(10)$ & $12(60)$ \\
\hline Asarcık & 20 & $4(20)$ & $2(10)$ & $2(10)$ & - & $8(40)$ \\
\hline Salıpazarı & 20 & $4(20)$ & $4(20)$ & $4(20)$ & - & $12(60)$ \\
\hline Tekkeköy & 20 & $4(20)$ & $4(20)$ & $2(10)$ & - & $10(50)$ \\
\hline Yakakent & 20 & $4(20)$ & $4(20)$ & $2(10)$ & - & $10(50)$ \\
\hline Atakum & 10 & $2(20)$ & $2(20)$ & - & - & $4(40)$ \\
\hline Canik & 10 & $2(20)$ & $2(20)$ & - & - & $4(40)$ \\
\hline İlkadım & 10 & $2(20)$ & $2(20)$ & - & - & $4(40)$ \\
\hline Ayvacık & 4 & $2(50)$ & $2(50)$ & - & - & $4(100)$ \\
\hline Toplam & 1000 & $100(10)$ & 92(9.2) & $48(4.8)$ & $32(3.2)$ & $272(27.2)$ \\
\hline
\end{tabular}

Tablo 3. Enterokok türlerinin antibiyotik direnç/duyarlılık patternleri

\begin{tabular}{|c|c|c|c|c|c|c|c|c|c|c|c|}
\hline & \multirow{2}{*}{ 产 } & \multicolumn{2}{|c|}{ 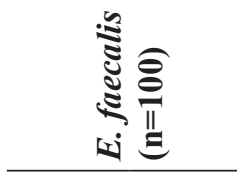 } & \multicolumn{2}{|c|}{ 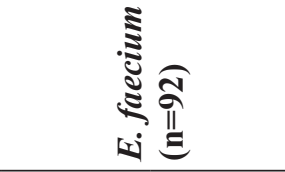 } & \multicolumn{2}{|c|}{ : ثِ } & \multicolumn{2}{|c|}{ 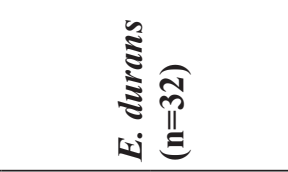 } & \multicolumn{2}{|c|}{ 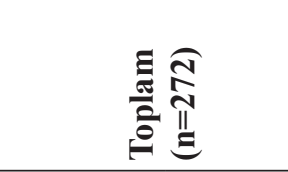 } \\
\hline & & S (\%) & R (\%) & S (\%) & R (\%) & S (\%) & R (\%) & S (\%) & R (\%) & S (\%) & R (\%) \\
\hline 1 & VA & $96(96)$ & $4(4)$ & $90(97.8)$ & $2(2.2)$ & $48(100)$ & $0(0)$ & $30(93.8)$ & $2(6.2)$ & $264(97.1)$ & $8(2.9)$ \\
\hline 2 & TEİ & $96(96)$ & $4(4)$ & $90(97.8)$ & $2(2.2)$ & $48(100)$ & $0(0)$ & $30(93.8)$ & $2(6.2)$ & $264(97.1)$ & $8(2.9)$ \\
\hline 3 & $\mathrm{AM}$ & $90(90)$ & $10(10)$ & $92(100)$ & $0(0)$ & $46(95.8)$ & $2(4.2)$ & $30(93.8)$ & $2(6.2)$ & $258(94.9)$ & $14(5.1)$ \\
\hline 4 & AN & $74(74)$ & $26(26)$ & $80(87)$ & $12(13)$ & $36(75)$ & $12(25)$ & $26(81.3)$ & $6(18.7)$ & $216(79.4)$ & $56(20.6)$ \\
\hline 5 & B & $80(80)$ & $20(20)$ & $88(95.7)$ & $4(4.3)$ & $38(79.2)$ & $10(20.8)$ & $24(75)$ & $8(25)$ & $230(84.6)$ & $42(15.4)$ \\
\hline 6 & $\mathrm{E}$ & $70(70)$ & $30(30)$ & $60(65.2)$ & $32(34.8)$ & $34(70.8)$ & $14(29.2)$ & $20(62.5)$ & $12(37.5)$ & $184(66.2)$ & $88(33.8)$ \\
\hline 7 & GM & $76(76)$ & $24(24)$ & $78(84.8)$ & $14(15.2)$ & $38(79.2)$ & $10(20.8)$ & $24(75)$ & $8(25)$ & $216(79.4)$ & $56(20.6)$ \\
\hline 8 & $\mathrm{P}$ & $84(84)$ & $6(6)$ & $84(91.3)$ & $8(8.7)$ & $44(91.7)$ & $4(8.3)$ & $28(87.5)$ & $4(12.5)$ & $252(92.6)$ & $20(7.4)$ \\
\hline 9 & CFP & $98(98)$ & $2(2)$ & $86(93.5)$ & $6(6.5)$ & $42(87.5)$ & $6(12.5)$ & $22(68.8)$ & $10(31.2)$ & $248(91.2)$ & $24(8.8)$ \\
\hline 10 & $\mathrm{~S}$ & $74(74)$ & $26(26)$ & $82(89.1)$ & $10(10.9)$ & $40(83.3)$ & $8(16.7)$ & $20(62.5)$ & $12(37.5)$ & $218(80.1)$ & $54(19.9)$ \\
\hline 11 & $\mathrm{TE}$ & $70(70)$ & $30(30)$ & $76(82.6)$ & $16(17.4)$ & $32(66.7)$ & $16(33.3)$ & $22(68.8)$ & $10(31.2)$ & $200(73.5)$ & $72(26.5)$ \\
\hline 12 & SXT & $98(98)$ & $2(2)$ & $90(97.8)$ & $2(2.2)$ & $46(95.8)$ & $2(4.2)$ & $28(87.5)$ & $4(12.5)$ & $262(96.3)$ & $10(3.7)$ \\
\hline
\end{tabular}


Tablo 4. İzole edilen enterokok türlerinde belirlenen çoğul antibiyotik direnç patternleri

\begin{tabular}{|c|c|c|c|c|c|c|}
\hline Antibiyotik Sayısı & Antibiyotik Direnç Fenotipi & 悹 & 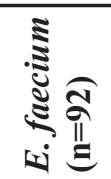 & 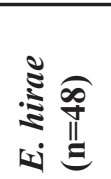 & 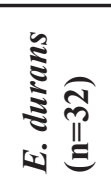 & Toplam $(n=272)$ \\
\hline 9 & VA-AM-B-E-GM-P-CFP-S-SXT & 1 & - & - & 1 & 2 \\
\hline 8 & AM-AN-GM-P-CFP-S-TE-SXT & 1 & 1 & - & & 2 \\
\hline 7 & AN-B-E-GM-CFP-S-SXT & 1 & - & - & 1 & 2 \\
\hline \multirow{2}{*}{5} & AM-AN-E-P-S & 1 & 1 & - & - & \multirow{2}{*}{4} \\
\hline & AN-B-GM-S-TE & 1 & - & 1 & - & \\
\hline \multirow{5}{*}{4} & AM-AN-E-GM & 1 & 1 & - & - & \multirow{5}{*}{10} \\
\hline & AN-B-GM-TE & 1 & - & 1 & 1 & \\
\hline & AN-GM-S-TE & 1 & - & - & - & \\
\hline & AN-E-GM-S & 1 & 1 & 1 & - & \\
\hline & B-GM-P-TE & 1 & - & - & - & \\
\hline \multirow{12}{*}{3} & TEI-B-TE & 1 & 2 & - & 1 & \multirow{12}{*}{30} \\
\hline & AM-E-TE & 1 & - & - & - & \\
\hline & AM-GM-S & 1 & 1 & 1 & - & \\
\hline & AN-B-TE & 1 & 1 & 1 & 1 & \\
\hline & AN-P-TE & 1 & 1 & - & - & \\
\hline & AN-CFP-TE & 1 & - & 1 & 1 & \\
\hline & AN-S-TE & 1 & 2 & - & - & \\
\hline & B-E-GM & 1 & - & - & - & \\
\hline & B-E-P & 1 & - & 1 & - & \\
\hline & B-GM-TE & 1 & 1 & - & 1 & \\
\hline & B-S-TE & 1 & - & - & - & \\
\hline & E-CFP-SXT & 1 & 1 & 1 & - & \\
\hline \multirow{22}{*}{2} & VA-TEI & 2 & 2 & 1 & - & \multirow{20}{*}{76} \\
\hline & TEI-S & 2 & 1 & 1 & 1 & \\
\hline & AM-AN & 2 & 1 & 1 & 1 & \\
\hline & AN-E & 2 & 1 & 2 & 1 & \\
\hline & AN-GM & 1 & 2 & 2 & 1 & \\
\hline & AN-S & 2 & 1 & 2 & 2 & \\
\hline & AN-TE & 4 & 1 & 2 & 1 & \\
\hline & B-E & 2 & 1 & 1 & 1 & \\
\hline & B-GM & 2 & 1 & 1 & 1 & \\
\hline & B-S & 4 & 1 & 1 & 1 & \\
\hline & E-GM & 2 & 1 & 1 & 1 & \\
\hline & E-P & 1 & 2 & 1 & 1 & \\
\hline & E-S & 6 & 1 & 2 & 1 & \\
\hline & E-CFP & 4 & 1 & 1 & 2 & \\
\hline & E-TE & 2 & 1 & 1 & 1 & \\
\hline & GM-S & 2 & 1 & 2 & 1 & \\
\hline & GM-TE & 1 & 2 & 3 & 1 & \\
\hline & P-SXT & 4 & 1 & 2 & 1 & \\
\hline & CFP-TE & 1 & 1 & 1 & 2 & \\
\hline & S-TE & 4 & 1 & 2 & 1 & \\
\hline & \multirow{2}{*}{ Toplam } & 50 & 24 & 30 & 22 & 126 \\
\hline & & $\% 50$ & $\% 26.1$ & $\% 62.5$ & $\% 68.8$ & $\% 46.3$ \\
\hline
\end{tabular}


Vankomisin (VA, $30 \mu \mathrm{g}$ ), Teikoplanin (TEI, $30 \mu \mathrm{g}$ ), Ampisilin (AM, $10 \mu \mathrm{g}$ ), Amikasin (AN, $30 \mu \mathrm{g})$, Basitrasin $(\mathrm{B}, 10 \mu \mathrm{g})$, Eritromisin (E, 15 $\mu \mathrm{g})$, Gentamisin (GM, $10 \mu \mathrm{g})$, Penisilin $(\mathrm{P}, 10 \mu \mathrm{g})$, Sefoperazon (CFP, $75 \mu \mathrm{g})$, Streptomisin (S, $10 \mu \mathrm{g})$, Tetrasiklin (TE, $30 \mu \mathrm{g}$ ), Trimetofrin-Sülfamethaksol (SXT, 1.25 ve $23.75 \mu \mathrm{g}$ )

\section{Tartışma}

Enterokoklar insan ve hayvan barsak florasının bir parçası olmaları, gıda sektöründe bazı türlerin çok güvenli olmasa da kullanılıyor olmasına rağmen, zaman zaman önemli hastalık vakalarından izole edilmektedirler. Enterokok türlerinin farklı kaynaklardan izolasyonu ve karakterizasyonu amaciyla çok sayıda çalışma yapılmıştır $[3,6,7,10,11]$. Ancak mandalarda enterokok türlerinin belirlenmesine yönelik çalışma sayısı yetersizdir.

Yabani ve evcil mandalarda zoonoz karaktere de sahip pek çok etkenin varlığı ve yaygınlığ araştırılmıştır [12, 17, 16, 19, 20].

Yapılan literatür incelemesinde, manda dışkılarından enterokok türlerinin tespitine yönelik çalışma sayısının çok sınırlı olduğu görülmektedir [14, 23]. Diğer yandan, yürütülen çalışmalar daha çok manda sütlerinden enterokok türlerinin belirlenmesine yöneliktir [1, 5, 9, 22, 24, 25]. Mandalarda yapılan çalışmaların sınırlı kalmasının belki de en önemli nedenleri; mandaların spesifik coğrafik bölgelerde lokalize olması ve popülasyonunun ülkeden ülkeye değişkenlik göstermesinden kaynaklanabilir.

Yaban hayatındaki mandalarda gerçekleştirilen bir çalışmada [23] incelenen 2 adet dışkı örneğinden 1'inden (\%50) E. hirae izole edilmiştir. Benzer bir araştırmada [14], 35 manda dışkısından 23 'ü (\%65.7) Enterococcus faecium, 4'ü (\%11.4) E. hirae ve 2'si (\%5.7) E. faecalis olmak üzere toplam 29 enterokok türü izole edilmiştir. İzolatların 15 'i tetrasikline, 10 'u sülfamataksasol+trimetoprime, 14'ünün eritromisine, 10'unun gentamisine ve 12'sinin de ampisiline dirençli olduğu bildirilmiştir.

$\mathrm{Bu}$ araştırmada, incelenen 1000 dışk1 örneğinin 100'ünden (\%10) E. faecalis, 92'sinden (\%9.2) E. faecium, 48'inden (\%4.8) E. hirae ve 32 'sinden $(\% 3.2)$ da E. durans olmak üzere, toplam 272 (\%27.2) enterokok izole ve identifiye edildi. İzolatlar vankomisin ve teikoplanine $\% 2.9$, trime- tofrin-sülfamethaksole $\% 3.7$, ampisiline $\% 5.1$, penisiline $\% 7.4$, sefoperazone $\% 8.8$, basitrasine $\% 15.4$, streptomisine $\% 19.9$, amikasin ve gentamisine $\% 20$ .6 , tetrasikline $\% 26.5$ ve eritromisine $\% 33.8$ oranında dirençli bulundu. 272 izolatın 126'sında (\%46.3) iki ve daha fazla antibiyotiğe direnç tespit edilmesi, çoğul antibiyotik dirençliliği açısından önemli olarak değerlendirildi.

Manda dışkılarından enterokok türlerinin ayrıntılı olarak araştırıldı $\breve{g}_{1}$ çalışmaya rastlanılamadığg için bölgemizdeki manda populasyonlarından izole edilen enterokok türleri ve izolasyon oranları detaylı olarak tartışılamadi. Ancak, konuyla ilgili bilgiye ulaşılan iki literatür $[14,23]$ verisindeki oranların, bu çalışma bulgularında daha yüksek olduğu görüldü. Bu çalışmada manda dışkılarının klinik olarak sağlıklı hayvan populasyonlarından elde edilmiş olması, diğer iki çalışma verileri ile farklılığı açıklayabilir. Diğer yandan çalışmalarda kullanılan metot ve örnek toplanan coğrafik bölge farkl1lıkları sonuçları etkileyebilmektedir.

Antibiyotiklere dirençli enterokok kökenli hastane enfeksiyonları güncelliğini korumaktadır [15]. $\mathrm{Bu}$ açıdan antibiyotiklere dirençli diğer bakterilerle mücadelede olduğu gibi uygun koruma ve kontrol programlarının belirlenmesi önem arz etmektedir. Antibiyotiklere dirençli enterokok türlerinin insanlara bulaştırılmasında, insanlarla yakın temas halinde olan hayvanlar önemli rol oynamaktadır. Etkenlerde belirlenen çoğul antibiyotik dirençlilikleri, sadece kendi aralarında değil diğer etkenlere de dirençliliğin genetik olarak aktarılması, artan patojen özelliklerinin insan ve hayvan sağlığını yakından ilgilendirmesi nedeniyle konu ile ilgili daha ayrıntılı çalışmaların yapılmasını zorunlu hale getirmektedir.

Sonuç olarak, bu çalışma ile bölgemizde ilk kez Anadolu Mandalarına ait dışkı örneklerinde enterokok türlerinin tespiti ve antibiyotik duyarlılık patternleri incelendi. Bölgemizde yetiştiriciliği yapılan mandalarda enterokok türlerinin dağılımı ve çeşitliliği ortaya konuldu. Diğer hayvan türlerinde yapılan çalışmalarda olduğu gibi baskın enterokok türlerin, $E$. faecalis ve E. faecium olduğu görüldü. İzolatlar arasında en fazla dirençliliğin eritromisin ve tetrasikline olduğu belirlendi. İzole edilen 272 enterokok suşunun 126 'sında (\%46.3) iki ve daha fazla antibiyotiğe direnç tespit edilmesi, çoğul antibiyo- 
tik dirençliliği açısından önemli olarak değerlendirildi. Daha ileri düzey çalışmalar ile mandalardan izole edilen bakterilerin direnç patternlerini ortaya konulması gerektiği kanısına varıldı.

\section{Teşekkür}

Bu çalışma PYO.VET.1904.14.006 numaralı yüksek lisans tez projesi kapsamında gerçekleştirilmiştir.

\section{Kaynaklar}

1. Andrighetto C, Knijff E, Lombardi A, Torriani S, Vancanneyt M, Kersters K, Swings J, Dellaglio F, (2001). Phenotypic and genetic diversity of enterococci isolated from Italian cheeses. J Dairy Res. 68(2), 303-316.

2. Anonim, (2018). Gıda, Tarım ve Hayvancılık Bakanlığı, Hayvancılık Genel Müdürlüğü, Ocak 2018 Verileri, Erişim adresi: http://www.tarim.gov.tr/sgb/Belgeler/SagMenuVeriler/ HAYGEM.pdf, Erişim Tarihi: 10.01.2018.

3. Boynukara B, Ekin İH, Aksakal A, Gülhan T, (2002). Insan, köpek ve kedi dişkllarından enterokokların izolasyonu ve antibiyotiklere duyarlılıkları. Veteriner Hekimleri Mikrobiyoloji Dergisi. 2(1), 37-42.

4. Clinical and Laboratory Standards Institute (CLSI) (2013). Performance standards for antimicrobial susceptibility testing; twenty-third informational supplement M100-S23. Wayne, PA.

5. Coppola S, Parente E, Dumontet S, Lapeccerella A, (1988). The microflora of natural whey cultures utilized as starters in the manufacture of Mozzarella Cheese from water-buffalo milk. Le Lait. 68(3), 295-309.

6. Çiftci A, Diker KS, (2009). The role of enterococcal virulence factors on experimental amyloid arthropathy in chickens. FEBS J. 276, 305.

7. Çiftci A, Fındık A, İça A, Baş B, Onuk EE, Güngördü S, (2009). Slime production and antibiotic resistance of Enterococcus faecalis isolated from arthritis in chickens. J Vet Med Sci. 71(6), 849-853.

8. Enany ME, Riad EM, Wahdan A, (2012). Bacterial causes of pneumonia in buffalo calves. SCVMJ. 17(2), 27-38.

9. Gelsomino R, Vancanneyt M, Condon S, Swings J, Cogan TM, (2001). Enterococcal diversity in the environment of an Irish Cheddar-type cheese making factory. Int J Food Microbiol. 71(2), 177-188.

10. Gülhan T, Aksakal A, Ekin İH, Savaşan S, Boynukara B, (2006). Virulence factors of Enterococcus faecium and Enterococcus faecalis strains isolated from human and pets. Turk J Vet Anim Sci. 30, 477-482.

11. Gülhan T, Boynukara B, Durmuş A, Kiziroğlu I, Sancak YC, (2012). Enteric bacteria and some pathogenic properties of Enterococcus faecalis, Enterococcus faecium and Escherichia coli strains isolated from wild ducks and gulls. Fresen Environ Bull. 21(7), 1961-1966.

12. Hadimli HH, Pinarkara Y, Sakmanoğlu A, Sayin Z, Erganiş O, Uslu A, Al-Shattrawi HJ, (2017). Serotypes of Salmonella isolated from feces of cattle, buffalo, and camel and sensitivities to antibiotics in Turkey. Turk J Vet Anim Sci. 41, 193-198.
13. Jahan M, Holley RA, (2016). Transfer of antibiotic resistance from Enterococcus faecium of fermented meat origin to Listeria monocytogenes and Listeria innocua. Lett Appl Microbiol. 62, 304-310.

14. Katakweba AAS, Møller KS, Muumba J, Muhairwa AP, Damborg P. Rosenkrantz JT, Minga UM, Mtambo MMA, Olsen JE, (2014). Antimicrobial resistance in faecal samples from buffalo, wildebeest and zebra grazing together with and without cattle in Tanzania. J Appl Microbiol. 118, 966-975.

15. Kim MC, Cha MH, Ryu JG, Woo GJ, (2017). Characterization of vancomycin-resistant Enterococcus faecalis and Enterococcus faecium isolated from fresh produces and human fecal samples. Foodborne Pathog Dis. 14(4), 195-201.

16. Mahanti A, Samanta I, Bandopaddhay S, Joardar SN, Dutta TK, Sar TK, (2014). Isolation, molecular characterization and antibiotic resistance of Enterotoxigenic E. coli (ETEC) and Necrotoxigenic E. coli (NTEC) from healthy water buffalo. Vet Arhiv. 84(3), 241-250.

17. Nuhay Ç, Gülhan T, (2017). Samsun ili ve ilçelerinde yetiştirilen Anadolu mandalarının dişk örneklerinde Escherichia coli O157:H7'nin tespiti. Etlik Veteriner Mikrobiyoloji Dergisi, 28 (1), 39-45, 2017.

18. Olsen RH, Schønheyder HC, Christensen H, Bisgaard M, (2012). Enterococcus faecalis of human and poultry origin share virulence genes supporting the zoonotic potential of $E$. faecalis. Zoonoses Public Hlth. 59 256-263.

19. Rahimi E, Momtaz H, Behzadnia A, Baghbadorani ZT, (2014). Incidence of Listeria species in bovine, ovine, caprine, camel and water buffalo milk using cultural method and the PCR assay. Asian Pac J Trop Dis. 4(1), 50-53.

20. Rehman MU, Rashid M, Sheikh JA, Bhat MA, (2014). Molecular epidemiology and antibiotic resistance pattern of Enteropathogenic Escherichia coli isolated from bovines and their handlers in Jammu, India. J Adv Vet Anim Res. 1(4), 177181.

21. Sharifi Y, Hasani A, Ghotaslou R, Naghili B, Aghazadeh M, Milani M, Bazmani A, (2013). Virulence and antimicrobial resistance in enterococci isolated from urinary tract infections. Adv Pharm Bull. 3(1), 197-201.

22. Teixeira LM, Merquior WLC, Vianni MCE, Carvalho MGS, Fracalanzza SEL, Steigerwalt AG, Brenner DJ, Facklam RR, (1996). Phenotypic and genotypic characterization of atypical Lactococcus gawieae strains isolated from water buffalos with subclinical mastitis and confirmation of L. gawieae as a senior subjective synonym of Enterococcus seriolicida. Int J Syst Bacteriol. 46(3), 664-668.

23. Thamacharoensuk T, Thongchul N, Taweechotipatr M, Tolieng V, Kodama K, Tanasupawat S, (2013). Screening and characterization of lactic acid bacteria from animal faeces for probiotic properties. Thai J Vet Med. 43(4), 541-551.

24. Turanta F, Unluturk A, Goktan D, (1989). Microbiological and compositional status of Turkish white cheese. Inter J Food Microbiol. 8(1), 19-24.

25. Villani F, Coppola S, (1994). Selection of enterococcal strains for water-buffalo Mozzarella cheese manufacture. Ann Microbiol Enzimol. 44, 97-105.

26. Whitman WB, Goodfellow M, Kämpfer P, Busse HJ, Trujillo ME, Ludwig W, Suzuki KI, (2012). Bergey's Manual of Systematic Bacteriology, 2nd ed., vol. 5, parts A and B, Springer-Verlag, New York, NY. 